\title{
Ecocardiografía en la sala de urgencias, intensivo y perioperatorio
}

\section{Ultrasound in emergency, intensive care and perioperative period}

María Carolina Cabrera Schulmeyer ${ }^{1}$

\begin{abstract}
Both transthoracic and transesophageal echocardiography have allowed a significant improvement in cardiovascular monitoring. With adequate training and in the search for specific answers, echocardiography can be very useful.

\section{RESUMEN}

La ecocardiografía tanto transtorácica como transesofágica han permitido una mejoría importante en la monitorización cardiovascular. Con un adecuado entrenamiento y en la búsqueda de respuestas puntuales la ecocardiografía puede ser de gran utilidad.
\end{abstract}

\section{Key words:}

Echocardiography, transthoracic, transesophageal

\section{Palabras clave: \\ Ecocardiografía, transtorácica, transesofágica}

a ecocardiografía llegó para quedarse a las unidades de pacientes inestables y críticos como es la sala de urgencias, la unidad de cuidado intensivo y el quirófano. La posibilidad de realizar el examen "al lado" de la cama del paciente de manera no invasiva (transtorácico) como de manera semiinvasiva (transesofágico) ha demostrado su alta utilidad como herramienta diagnóstica y de monitorización, ya que la información que aporta puede resultar en nuevos diagnósticos, optimización y/o cambios en la terapia de los pacientes.
Desde la introducción de la ecocardiografía transesofágica (ETE) hace 30 años para monitorización y diagnóstico de cirugías cardíacas, sus indicaciones y utilidades se han expandido rápidamente a cirugías no cardíacas y al cuidado intensivo. Se trata de un sistema de monitorización cuantitativo y cualitativo que permite estimar volúmenes, presiones, contractilidad miocárdica y parámetros como precarga y postcarga para así vigilar, guiar terapias y realizar diagnósticos. La ecocardiografía es un monitor muy útil para la evaluación fisiológica cardiovascular porque se estudian

Profesor auxiliar de anestesiología Universidad de Valparaíso sede Hospital FACh.

Ecocardiografista Imperial College of London, Hammersmith Hospital.

Fecha de recepción:

Fecha de aceptación:

ORCID

0000-0002-6105-5780

Correspondencia:

María Carolina Cabrera Schulmeyer

maria.cabrera@uv.cl 
los volúmenes y las presiones cardíacas simultáneamente, pudiéndose determinar en qué parte de la curva de Frank Starling trabaja el ventrículo izquierdo (VI).

Para la óptima utilización de la ecocardiografía se requiere de un adecuado conocimiento de la anatomía y fisiología cardiaca, así como de los principios del ultrasonido. También se debe estar familiarizado con el equipo, para ajustar los límites de los colores y las velocidades para obtener imágenes de alta calidad.

La ecocardiografía que se realiza en estas unidades, dadas las diferentes situaciones de inestabilidad hemodinámica debe ser focalizada, es decir, intentar responder preguntas muy puntuales que permitan cambiar las conductas.

\section{Ecocardiografía transtorácica focalizada (ETT)}

\section{¿Por qué ecocardiografía focalizada?}

La monitorización hemodinámica corresponde a una de las actividades fundamentales que realiza un médico a un paciente crítico (unidad de cuidado intensivo, emergencias y quirófano). Esta actividad de vigilancia realizada con ecocardiografía ha demostrado ser de alta utilidad. Esta evaluación ecocardiográfica no pretende reemplazar el examen ecocardiográfico que realiza un cardiólogo en el laboratorio de ecocardiografía, puesto que sus objetivos son claramente diferentes[1]. La ETT focalizada busca acotar un problema hemodinámico, diagnosticando o descartando etiologías, para en base a ello decidir la mejor alternativa terapéutica[2],[3],[4].

Como la edad de la población ha aumentado en forma significativa, cada vez más pacientes son portadores de patologías cardiovasculares crónicas, como hipertensión, cardiopatía coronaria y valvulopatías. Este tipo de enfermos complejos, ingresan a unidades de cuidado crítico, a unidades de emergencias o son programados para diferentes cirugías generales y requieren de monitorización cardiovascular muy precisa.

Ya ha sido bien validada la utilización de ecocardiografía transesofágica (ETE) en anestesiología y cuidado crítico, tanto para monitorización como para diagnóstico durante cirugía cardíaca como no cardíaca. La ETE ha sido objeto de una importante cantidad de investigación con buenos resultados.

Las mayores limitantes de la ETE son la disponibilidad de la sonda transesofágica, que tiene una vida útil dada por el número de exámenes que se pueden realizar con ella (alrededor de 1.000), el entrenamien- to del operador y la necesidad de sedación profunda o anestesia general para introducirla a través del esófago y mantener la vigilancia continua.

Aquí es donde la ETT puede ser una herramienta útil, ya que es una técnica de imagenología cardíaca no invasiva que puede aportar gran cantidad de información importante al momento de tomar decisiones en estos pacientes complejos con protocolos acotados y focalizados a responder preguntas simples, pero decisivas.

Sus principales beneficios son la combinación entre su bajo grado de invasividad al compararlo con una línea arterial, catéter venoso central o catéter de arteria pulmonar versus la gran cantidad de información sobre la función cardiaca y característica de los grandes vasos que ésta puede entregar en tiempo real en pocos minutos[5],[6],[7].

El desarrollo de equipos ecocardiográficos portátiles de buena calidad y de costos no muy elevados, ha permitido que muchos médicos de especialidades diferentes a la cardiología realicen ecoscopías. Ahora bien, claramente se trata de equipos más simples, pero con una calidad de imágenes suficiente para realizar diagnósticos focalizados en el paciente crítico. Como se verá en las imágenes, la calidad de estos es claramente inferior a aquéllos obtenidos por los cardiólogos.

Además, en el caso de los pacientes monitorizados en el quirófano existen importantes interferencias como son el pulmón y el uso de electrobisturí. Los pacientes en su mayoría no están en decúbito lateral, se encuentran en situaciones críticas y, además, pueden estar intubados y tener drenajes torácicos, todo lo cual dificulta la visualización con ultrasonido.

Desde hace ya varios años se utiliza ETT focalizada en urgencias para la evaluación de pacientes politraumatizados, enfermos con antecedentes cardiovasculares previos y en la sala de reanimación en casos de paro cardiaco.

En las unidades de cuidados intensivos también se ha producido este auge por la ecocardiografía, tanto transtorácica como transesofágica. En estas unidades se ha demostrado que con las imágenes cardiacas en tiempo real obtenidas con ecocardiografía se logra un adecuado diagnóstico etiológico de la causa del compromiso del estado hemodinámico[8],[9],[10]. Pero por las mismas razones que en el quirófano, en el caso de la ETT, en $10 \%$ a $30 \%$ de los pacientes no se pueden obtener imágenes adecuadas, debido al uso de ventilación mecánica, a la presencia de drenajes torácicos y por no poder posicionar de manera adecuada al paciente.

En anestesiología, sólo desde hace un par de años 
se inició el desarrollo e introducción de ecocardiografía transtorácica al quirófano. Siempre se argumentó que los ecógrafos de gran tamaño eran un estorbo en este ambiente y que la calidad de las imágenes en general era mala. Esto último debido a no poder cambiar al paciente a posición decúbito lateral izquierdo, la interferencia del ventilador mecánico y del campo quirúrgico. Con el advenimiento de equipos portátiles del tamaño de un computador personal y actualmente el de un teléfono, que han incorporado la tecnología que se requiere, es que comenzó a desarrollarse la ecografía transtorácica perioperatoria realizada por anestesiólogos[11],[12].

Así entonces, la ETT focalizada es una técnica de monitorización no invasiva, que entrega imágenes en tiempo real de las cavidades cardíacas y de sus grandes vasos. También a través de mediciones sencillas con doppler ya sea color, pulsado, continuo o tisular, es posible obtener estimaciones de los volúmenes, presiones y gradientes, como ya se ha dicho, al lado de la cama del paciente.

\section{Instrumentación y planos de estudio de un examen ecocardiográfico focalizado}

Para realizar ETT bidimensional se utiliza un transductor electrónico que emite ondas de frecuencias entre 3 y $5 \mathrm{MHz}$. Los transductores tienen un indicador en uno de sus lados que muestra la dirección del plano del ultrasonido. Éste también señala las estructuras que aparecerán a la derecha de la imagen en pantalla (Figura 1).

\section{Planos de sección}

El corazón y sus grandes vasos son estructuras tridimensionales sobre las cuales es posible trazar ejes y a lo largo de estos ejes se pueden dibujar planos de sección. Habitualmente, se habla de eje largo, eje corto y visión de 4 cavidades.

- Planos en eje largo: corresponden a las imágenes ecocardiográficas paralelas al eje mayor del corazón.

- Planos en eje corto: corresponden a las imágenes ecocardiográficas paralelas al eje menor del corazón.

- Plano de cuatro cavidades: estas visiones están relacionadas con el eje mayor del corazón y pueden ser observadas desde la posición apical o subcostal.

Se recomienda seguir una secuencia predetermi-

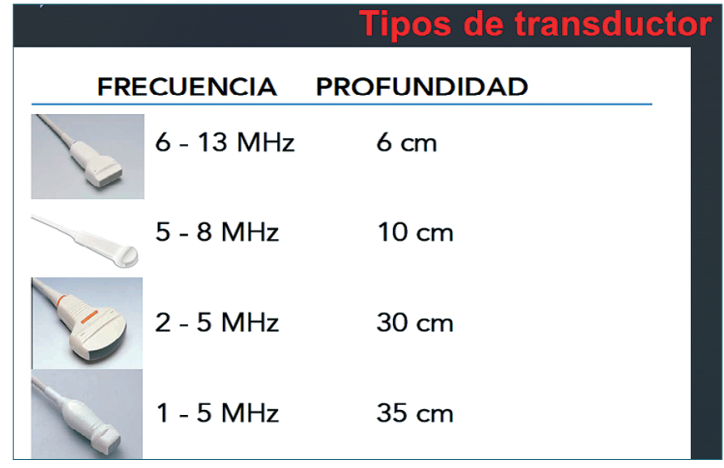

Figura 1. Tipos de transductor.

nada de imágenes para realizar un estudio ecocardiográfico focalizado.

\section{Grupo 1: Imágenes paraesternales en eje largo $y$ corto}

El transductor se posiciona de manera horizontal o con el indicador del transductor dirigido hacia el hombro derecho, en la región paraesternal izquierda aproximadamente entre la $3^{a}$ y $4^{a}$ costillas (Figura 2 ).

En esta imagen se debe evaluar el ventrículo izquierdo $(\mathrm{VI})$, su tamaño y contractilidad. Se mide la pared posterior en modo 2D. Se observa la válvula mitral (vm), el estado de sus velos y con doppler color se puede estudiar su funcionalidad. También se visualiza la aurícula izquierda (Al) y se mide su tamaño en modo 2D. Se observa la válvula aórtica (va), sus velos y el tracto de salida, cuyo diámetro se mide en modo 2D. En esta visión se obtiene una buena imagen del ventrículo derecho (VD) que corresponde aproxima-

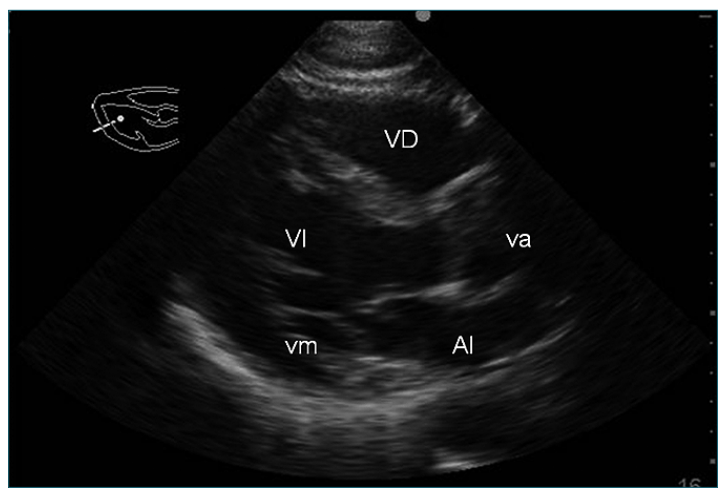

Figura 2. Eje largo paraesternal. Es un plano útil para estudiar el $\mathrm{VI}$ en su eje largo. $\mathrm{VI}=$ ventrículo izquierdo, $\mathrm{Al}=$ aurícula izquierda, $\mathrm{VD}=$ ventrículo derecho, $\mathrm{vm}=$ válvula mitral, va = válvula aórtica . 
damente al tracto de salida. El septum interventricular se continúa con la pared anterior de la aorta.

Rotando el transductor en $90^{\circ}$ en sentido horario, a posición vertical o con el indicador del transductor dirigido hacia el hombro izquierdo, se obtiene el eje corto paraesternal. Cuando la imagen del VI en la pantalla es circular, se puede afirmar con certeza que se está en eje corto (Figura 3). Así es posible evaluar el tamaño y la contractilidad del VI y VD. A nivel del $\mathrm{VI}$ se pueden obtener numerosas visiones de eje corto explorándolo en forma longitudinal, desde su nivel basal contiguo a la válvula mitral, pasando por los planos intermedios a nivel de las cuerdas tendíneas y los músculos papilares y terminando en el nivel apical. Del mismo modo, si la inclinación del transductor es más cefálica que aquella necesaria para obtener el plano mitral del VI, se puede obtener una imagen del eje corto de la válvula aórtica.

\section{Grupo 2: Imagen apical de 2, 4 y 5 cámaras}

El transductor se posiciona en el ápex cardiaco, habitualmente ubicado en el quinto espacio intercostal. El indicador del transductor debe orientarse hacia la izquierda del paciente, de esta manera, las cavidades cardiacas derechas se observan a la izquierda de la pantalla y las izquierdas a la derecha de ésta (Figura 4).

Esta visión muestra el corazón dividido en cuatro cavidades por el septum ventricular, por el septum auricular y por las válvulas mitral y tricúspide. El endocardio del VD es más trabeculado que el izquierdo y la válvula tricúspide tiene una inserción ligeramente desplazada hacia la región apical, lo que permite diferenciar ambas cavidades. En esta ventana se observa el VI, VD, Al y AD. Aquí también es posible evaluar la contractilidad del miocardio incluido el ápice del ventrículo izquierdo.

Esta visión es útil para realizar estudios con doppler cuantitativo (continuo o pulsado ya que la dirección del flujo sanguíneo a través de las válvulas se encuentra alineada con la dirección de las ondas de doppler enviadas desde el transductor, condición necesaria para realizar una evaluación adecuada de flujos intracardiacos mediante este recurso ecográfico.

Utilizando doppler pulsado a nivel de la apertura de los velos de la válvula mitral se obtiene la curva de llenado del VI, para evaluar su función diastólica que, en caso de ser normal, se caracteriza por una primera onda más alta correspondiente al llene rápido (E) y una segunda onda más baja debida a la contracción auricular (A). La relación de altura de estas dos ondas, permitirá diagnosticar los diferentes niveles de función diastólica ventricular.

Si desde la imagen de 4 cámaras se rota el trans-

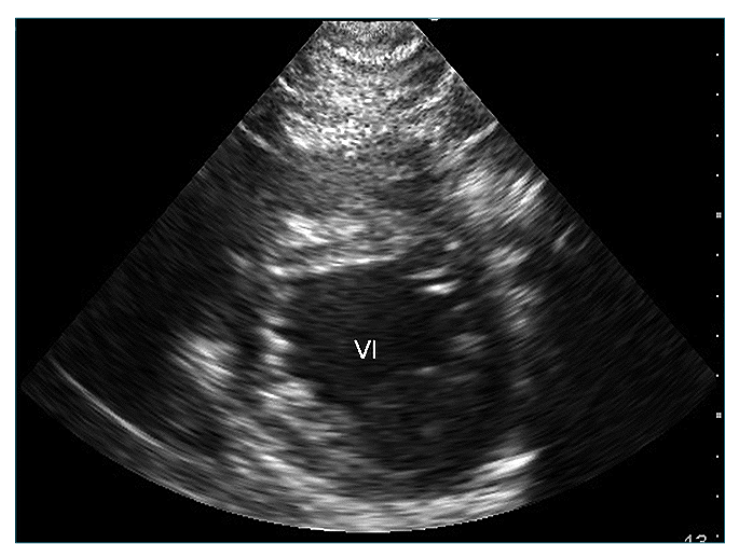

Figura 3. Eje corto paraesternal. Se observa el VI en un plano útil para evaluar isquemia.

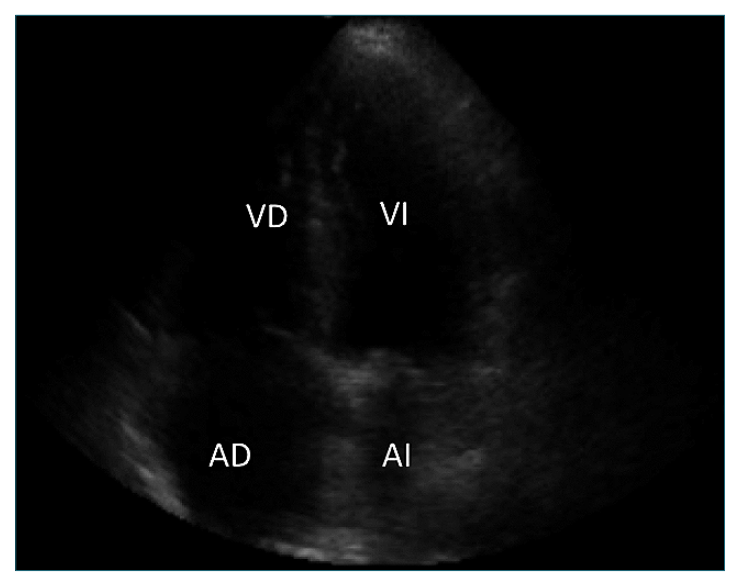

Figura 4. Visión desde 4 cámaras donde se observa VI, VD, Al y $A D$.

ductor en $90^{\circ}$, se obtendrá la imagen de 2 cámaras, en que desaparece el VD y la $A D$ y la visión de la vm es bicomisural. Esta imagen es útil para observar la orejuela izquierda y para evaluar la contractilidad de las paredes anterior e inferior del VI.

Si desde la imagen de 4 cámaras se inclina el transductor en sentido cefálico, se podrá observar el tracto de salida del VI y la va, que corresponde a la imagen de 5 cámaras. Como esta imagen también mantiene alineado el flujo transaórtico con el flujo del doppler, es posible realizar evaluaciones cuantitativas de dicho flujo. Utilizando doppler continuo a nivel de la va, se obtiene la velocidad máxima del flujo (V máx.) con la cual se puede calcular el gradientes de presiones transvalvular que dará cuenta de la magnitud de una eventual estenosis aórtica. 
Finalmente, utilizando doppler color, se puede evaluar la dirección de los flujos a través de las válvulas tricúspide, aórtica y mitral y si estos son lineales o turbulentos, informando respecto a posibles valvulopatías.

\section{Grupo 3: Imágenes subcostales}

En este caso el transductor debe desplazarse hacia la región subcostal en la línea media (se le llama también imagen subesternal o epigástrica) y rotarlo ligeramente hacia la izquierda (Figura 5). En esta ventana ecocardiográfica se obtiene una buena visión del corazón de manera global, en que se observan las 4 cámaras en sentido oblicuo, con la punta del corazón dirigida hacia la derecha de la pantalla y el VD ubicado hacia arriba. Esta imagen permite además una buena evaluación del pericardio.

Si desde esta imagen subcostal se rota el transductor en sentido antihorario en aproximadamente $90^{\circ}$ con leve inclinación hacia la derecha del paciente, es posible observar la vena cava inferior ( $\mathrm{VCl}$ ) a su llegada a la ad y evaluar su diámetro, correlacionándolo con la precarga. Su grado de colapsabilidad medido en modo M tiene que ver con la volemia. Así, si la VCI se colapsa en relación a la inspiración, se asume que existe hipovolemia, mientras que si mantiene un diámetro fijo, se correlaciona con hipervolemia.

\section{Examen transtorácico focalizado en paciente crítico, emergencias y anestesia}

El objetivo de esta evaluación ecocardiográfica focalizada es aportar al médico información básica para diagnosticar el estado hemodinámico y evaluar estructuras cardíacas, como válvulas, pericardio y miocardio para diagnosticar si su función es normal o anormal[13],[14],[15].

La idea es frente a preguntas básicas buscar una respuesta con la ecoscopía y así decidir la terapia más adecuada. Estas preguntas son:

1. ¿Cuál es el estado de la volemia?

2. ¿Cómo se contrae el corazón?

3. ¿Existe otra causa que explique el problema en el estado hemodinámico (por ejemplo, derrame o taponamiento cardíaco)?

La ecocardiografía transtorácica es una herramienta de monitorización de gran utilidad, que permite la vigilancia del corazón de forma no invasiva. Las imágenes que se obtienen son de razonable buena calidad, en tiempo real y al lado de la cama del paciente. Las posibles indicaciones son diversas y es

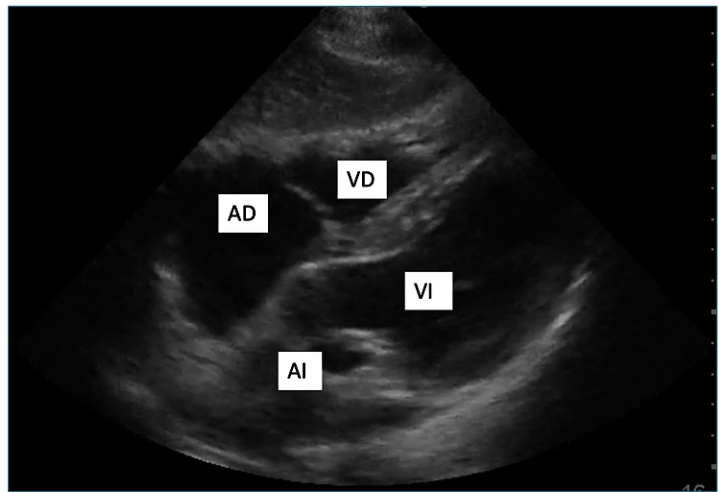

Figura 5. Imagen subcostal.

probable que irán aumentando, en la medida que existan operadores entrenados capaces de realizar un examen focalizado. La ETT permite determinar si existe una disfunción miocárdica severa, y estimar la volemia y la contractilidad miocárdica. Esta evaluación puede ser indicada tanto en el momento del deterioro hemodinámico agudo o como método de vigilancia y seguimiento. También es posible realizar ETT focalizada a pacientes que están bajo sedación antes de indicar métodos más invasivos como la instalación de una línea arterial o de un catéter venoso central.

El cuadro clínico de un paciente con compromiso hemodinámico: palidez, hipotensión, taquicardia, oliguria, es altamente inespecífico y puede derivar de situaciones disímiles como sangrado e hipovolemia, isquemia miocárdica, neumotórax hipertensivo, derrame pleural masivo, falla cardíaca o taponamiento cardiaco. Así, la ETT focalizada permitirá un diagnóstico de la causa y permitirá un tratamiento etiológico concomitante[16],[17],[18].

Existe un paradigma aplicado a la generalidad de los pacientes en estado crítico y es que cada vez que un paciente está hipotenso su tratamiento es, a todo evento, la administración de fluidos de cualquier tipo. Esto en los enfermos que realmente requieren volumen es beneficioso, pero en los casos en que el paciente está normovolémico o hipervolémico la administración de volumen puede ser ineficaz o francamente deletérea. Así que un punto muy importante que ha enseñado la ecocardiografía focalizada es que hipotensión no es sinónimo de hipovolemia.

\section{Indicaciones de ETT focalizada}

\section{a) Indicaciones de ecocardiografía focalizada en unidad de emergencia:}

Probablemente los médicos de urgencias fueron 
los pioneros en utilizar ultrasonido como parte de la evaluación del paciente politraumatizado, con pérdida de conciencia o abdomen agudo que ingresaba a sus unidades. El protocolo FAST (acrónimo del inglés, Focused Assessment Sonography in Trauma), es uno de los primeros protocolos que se comenzó a utilizar hace ya más de una década y uno de los más conocidos. Este protocolo busca básicamente la evaluación del abdomen, pero dada su cercanía con el diafragma, se utiliza la ventana subcostal para la evaluación de la presencia de derrame o taponamiento cardíaco secundario al trauma.

También existen protocolos para el uso de ecoscopía en el caso de un paro cadíaco. Se trata del protocolo FEEL (acrónimo del inglés, Focused Echocardiographic Evaluation in Life Support), que busca detectar causas tratables de actividad eléctrica sin pulso, incluyendo taponamiento cardiaco, embolia pulmonar masiva, disfunción ventricular severa e hipovolemia. Este protocolo podría también ayudar en la detección de fibrilación ventricular fina, difícil de diagnosticar por ECG de superficie, optimizando así la reanimación. También puede tener un rol en la detección precoz del retorno a la circulación. Su uso es recomendado en las guías de la American Heart Association (AHA), el European Resuscitation Council (ERC) y el International Liaison Committee on Resuscitation (ILCOR), cuyas directrices se centran en una RCP de alta calidad, con la mínima interrupción de las maniobras de compresión torácica para reducir los intervalos sin flujo. De este modo, en la actualidad el ultrasonido y la ecoscopía se utilizan de manera rutinaria en la sala de urgencias.

\section{b) Indicaciones de ecocardiografía focalizada en Unidad de Cuidados Intensivos:}

En esta área, la ecocardiografía ha alcanzado un desarrollo muy importante. No sólo la evaluación cardiaca, sino que el ultrasonido como una herramienta para realizar el examen físico de enfermos críticos hospitalizados en estas unidades ha demostrado gran eficiencia y detección precoz de complicaciones pulmonares, abdominales y trombosis venosa profunda. Permite cambiar diagnósticos y planes terapéuticos y controlar sus resultados.

En el examen ecocardiográfico se busca estudiar detalladamente la contractilidad segmentaria del miocardio, así como también analizar la función diastólica. Todo esto, orientado a evaluar el efecto de los diferentes fármacos vasoactivos y la visión directa del efecto de los inótropos en el miocardio, permite una titulación bastante precisa de las dosis óptimas a utilizar y, de este modo, combinar de manera óptima el uso de inótropos, volumen, vasodilatodores o vasoconstrictores.

Son justamente los intensivistas quienes han diseñado un plan de formación, con un sistema piramidal que incluye: desde un nivel básico, donde el operador debiera poder reconocer las estructuras cardíacas y decartar un taponamiento, hasta el vértice de ésta, donde se encuentra el operador experto.

\section{c) Ecocardiografía en anestesia:}

La ecocardiografía puede ser útil para la evaluación preoperatoria de muchos pacientes que son sometidos a cirugías de urgencia que no es posible suspender para profundizar el estudio cardiovascular. En los centros hospitalarios no siempre se cuenta con la posibilidad de realizar ecocardiografía las $24 \mathrm{~h}$ los 7 días de la semana. Contando con este examen ecocardiográfico focalizado, es posible para el anestesiólogo realizar una evaluación tendiente a hacer un diagnóstico funcional del corazón. Por otro lado, existe un número importante de pacientes ancianos a quienes no es posible evaluar su capacidad funcional, ya sea porque tienen compromiso neurológico o severo deterioro cognitivo. Este grupo, como por ejemplo, aquellos con fractura de cadera, se beneficia especialmente con este tipo de evaluación en el preoperatorio de una cirugía.

En el intraoperatorio, las imágenes que aporta la ecocardiografía transtorácica resultan fundamentales en el manejo anestésico de pacientes ancianos, cardiópatas, portadores de valvulopatías y pacientes obstétricas, por ejemplo, portadoras de preeclapsia y eclampsia. Por otra parte, durante el posoperatorio contar con ecocardiografía puede ser también de mucha utilidad. Una vez que el paciente sale del quirófano puede presentar compromiso hemodinámico, que clínicamente se traduzca en taquicardia e hipotensión. La ecocardiografía focalizada permitirá realizar diagnósticos diferenciales y así optimizar la terapia del enfermo.

En la actualidad en anestesiología existen varios protocolos de examen ecocardiográfico focalizado. Uno de ellos es el FATE (acrónimo del inglés, Focused Assessment with Transthoracic Echocardiography) que ha demostrado ser muy útil ante la presencia de shock durante el posoperatorio. Este examen ecocardiográfico, utilizando las 4 ventanas antes descritas más una ventana pleural, analiza el corazón, evaluando su llenado y contractilidad y las pleuras en la búsqueda de derrame pleural. El otro protocolo que ha demostrado su utilidad, pero durante el intraoperatorio es el HEART (acrónimo del inglés, Haemodynamic Echocardiography Assessment in Real Time), este exa- 
men ecográfico sigue un esquema bastante parecido al FATE, pero además, incluye el estudio de la válvula aórtica. El fundamento de estudiar esta válvula de manera dirigida es que con la edad se ha demostrado que tiende a estenosarse con la edad y teniendo en cuenta que el paciente portador de una estenosis aórtica tenderá a tener un gasto fijo, el diagnóstico de esta patología es de suma importancia para adaptar tanto la técnica anestésica como la terapia vasoactiva en el pabellón quirúrgico.

La ecocardiografía transtorácica perioperatoria es una técnica que está en pleno desarrollo actual y, en la medida que más anestesiólogos se entrenen, sus indicaciones y utilidades probablemente irán en aumento. En la actualidad existen simuladores para el aprendizaje de ecocardiografía transtorácica. Toda la evidencia apunta a que ésta es una excelente herramienta que permite un adecuado entrenamiento.

\section{Ecocardiografía transesofágica en Servicio de Ur- gencia, Cuidado Intensivo e Intraoperatorio}

La ETE requiere de un entrenamiento más profundo y el operador que la realiza debe saber interpretar adecuadamente las imágenes: en forma coloquial se podría sostener que "se ve lo que se sabe".

\section{Inserción del transductor:}

La introducción del transductor se realiza luego de la intubación del paciente. Siempre debe lubricarse éste antes de introducirlo, realizando los mismos movimientos que se usan para insertar una sonda orogástrica. Con la mano izquierda se puede traccionar suavemente la mandíbula y con la derecha se introdu- ce la sonda ecocardiográfica. La punta se dirige por la línea media hacia la orofaringe en forma suave y manteniéndolo en posición neutra, sin fijarlo nunca. Si existe alguna dificultad es recomendable utilizar laringoscopio para obtener visión directa[19],[20]. A alrededor de $30 \mathrm{~cm}$ de la arcada dentaria se obtienen las primeras imágenes del corazón.

No se recomienda el uso de profilaxis antibiótica de rutina para endocarditis bacteriana durante la monitorización intraoperatoria con ETE, salvo que se trate de un paciente de muy alto riesgo, o que forme parte de la profilaxis de la cirugía.

Una vez finalizado el examen el transductor debe ser lavado y desinfectado[21].

\section{Indicaciones:}

La ETE es un examen semiinvasivo, con una tasa muy baja de complicaciones. La formulación de guías permite actualizarlas en la medida que cambie la evidencia y la experiencia aumente. Las indicaciones de ETE también dependen del lugar y del tipo de pacientes donde se realice.

La ASA (Sociedad Americana de Anestesiología) recomienda en sus guías clínicas del 2014 las indicaciones enumeradas en la Tabla 1.

\section{Contraindicaciones:}

En cada paciente deben evaluarse riesgos versus beneficios al momento de realizar el procedimiento $y$, si los beneficios sobrepasan a los riesgos potenciales a los que se somete el paciente, la única contraindicación absoluta es la cirugía reciente $(<6$ semanas) de patología esofagogástrica. Eso sí, en el caso de existir dudas, se deben tomar precauciones, tales como: 1)

\section{Tabla 1. Cirugía cardíaca y de aorta torácica}

A todos los adultos que no tengan contraindicación para realizar ecocardiografía transesofágica esta debe indicarse

Cirugías cardíacas abiertas

Para confirmar o redefinir diagnósticos preoperatorios

Para diagnosticar nuevas patologías

Para ajustar el plan anestésico y quirúrgico de acuerdo a las imágenes

Para evaluar los resultados de la cirugía

Cirugías de revascularización miocárdica sin circulación extracorpórea

En procedimientos con cateterización intracardíaca e instalación de endoprótesis

Cirugía no cardíaca

A todos los pacientes en que por su patología cardiovascular preoperatoria o por el tipo de cirugía exista riesgo de compromiso severo hemodinámico, respiratorio o neurológico

En el caso de compromiso cardiocirculatorio severo que no responda a tratamiento

Cuidado crítico

A todos los pacientes críticos en que se piense que con ETE cambiará su manejo y en que no se haya obtenido imágenes satisfactorias con ecocardiografía transtorácica 
considerar otro tipo de técnica de imágenes (ecocardiografía epiaórtica); 2) interconsultar al gastroenterólogo; 3) usar transductores de menor tamaño, evitar la manipulación excesiva del transductor y 4) que el examen lo realice el operador más entrenado.

\section{Complicaciones:}

En cualquier grupo etario, la ETE intraoperatoria es un procedimiento con una tasa muy baja de complicaciones. Los riesgos potenciales son disfagia, parálisis de cuerdas vocales, daño dental, obstrucción de la vía aérea, extubación traqueal y compresión vascular. La perforación, daño y hematoma esofágico son las complicaciones más temidas, pero éstas en conjunto no sobrepasan el $1 \%$.

\section{Procedimiento estandarizado de ecografía transesofágica}

Se han propuesto una serie de 20 cortes esquemáticos para obtener todas las imágenes útiles para una evaluación global del corazón y sus grandes vasos. Cada imagen se designa según la localización del transductor (ventana ecocardiográfica), plano (eje largo o eje corto) y la estructura principal visualizada. El orden de obtención de las imágenes depende del operador y de la urgencia con que necesite hacer el diagnóstico. Si se trata de una emergencia se debe realizar una evaluación rápida inicial. Generalmente, ésta se realiza en la visión de cuatro cámaras o en el eje corto a nivel transgástrico, buscando diagnósticos en forma dirigida, para luego ir a visualizar y estudiar todas las estructuras.

Los planos que deben ser visualizados y los centímetros de profundidad, corresponden a la distancia promedio desde la arcada dentaria donde se obtienen. Dada la proximidad del esófago y el corazón y la ausencia de tejidos que se interpongan, la visión es en general de buena calidad. Existen, eso sí, variaciones anatómicas individuales, que imposibilitan la obtención de algunos cortes. Con el propósito de simplificar y ordenar el trabajo del operador en la realización del examen, se propone el siguiente esquema dividiéndolo en cuatro grandes grupos de imágenes. Se presentan las principales visiones de manera resumida:

\section{Esófago medio alto (aproximadamente entre 25 y $30 \mathrm{~cm}$ de la arcada dentaria)}

\section{Válvula aórtica en eje corto}

Se introduce el transductor hasta que se observen los velos; una vez ubicados, se debe cambiar el ángulo del transductor a $60^{\circ}$ (Figura 6).

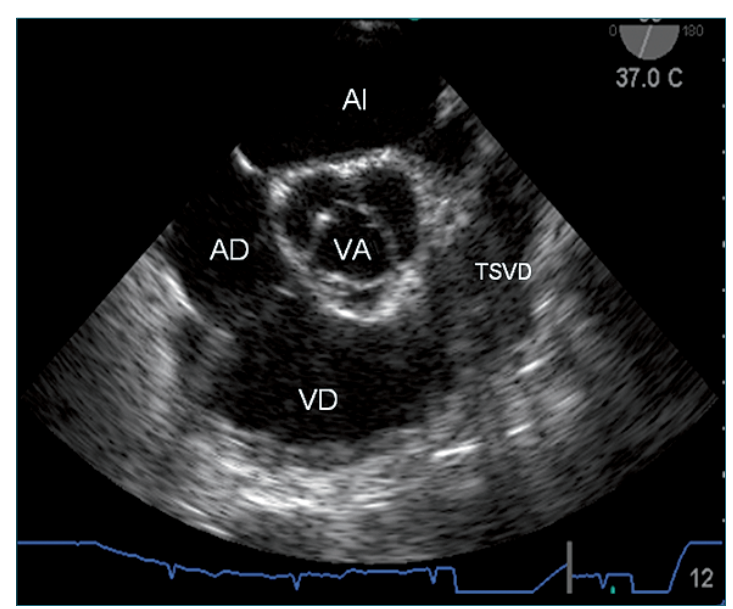

Figura 6. Imagen ecocardiográfica obtenida desde esófago alto que corresponde al estudio en eje corto de la válvula aórtica (VA). Se observa además la aurícula izquierda (AI), la aurícula derecha $(A D)$, el ventrículo derecho $(V D)$ y el tracto de salida del ventrículo derecho (TSVD).

Se estudia la anatomía de la válvula aórtica (bicúspide o tricúspide), si tiene calcificaciones y con doppler color se evalúa la presencia de reflujo o estenosis. En esta visión se puede evaluar también el tabique interauricular, la válvula tricúspide y el ventrículo derecho. En un plano ligeramente superior se encuentran las arterias coronarias que se estudian también con doppler color. También en esta visión se puede realizar un trazado planimétrico del área valvular, cuyos valores normales son entre 3 y $4 \mathrm{~cm}^{2}$.

\section{Válvula aórtica en eje largo}

En esta imagen el ángulo del transductor se rota a $110^{\circ}-130^{\circ}$, donde se observa en eje largo el tracto de salida del VI, la válvula aórtica y la aorta ascendente proximal (Figura 7).

Se puede analizar la presencia de insuficiencia aórtica y placas de ateroma en aorta. El diámetro del anillo valvular aórtico se mide durante la sístole y es normalmente entre 1,8 y $2,5 \mathrm{~cm}$. Esta ventana es, además, la mejor visión para medir la raíz de la aorta. También, en el caso de una disección de aorta, se puede observar el flap de disección, pero no siempre es posible observar el sitio donde canulan la aorta los cirujanos cardíacos.

\section{Esófago medio (aproximadamente entre 35-37 $\mathrm{cm}$ de la arcada dentaria)}

\section{Cuatro cámaras}

La imagen de cuatro cámaras constituye la mejor 


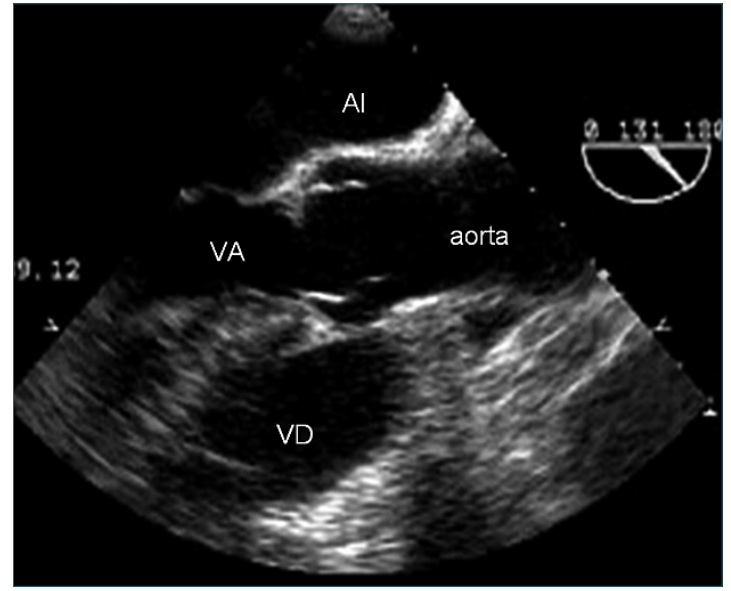

Figura 7. Imagen ecocardiográfica desde esófago alto que corresponde a una visión en eje largo del tracto de salida del VI y de la válvula aórtica.

visión para el estudio de la vm y su aparato subvalvular. La vm está formada por los velos anterior y posterior, cuerdas tendíneas, músculos papilares, annulus y paredes del VI. Ambos velos se unen por las comisuras anterolateral y posteromedial con su correspondiente músculo papilar (Figura 8).

En esta visión se puede estudiar la función diastólica del $\mathrm{VI}$, al igual que en la visión de 4 cámaras apical en el estudio transtorácico, utilizando doppler pulsado a través de la válvula mitral donde, como ya se señaló, se obtienen dos ondas: la primera corresponde al llene rápido del VI (onda E) y la segunda al llene lento, dependiente de la contracción auricular (onda A).

\section{Ventrículo izquierdo}

En esta posición se puede estimar el tamaño de la cavidad ventricular y observar su contractilidad segmentaria. El volumen diastólico final (VDF) normal es entre $50-00 \mathrm{ml}$ y el volumen sistólico final (VSF) es entre 30-60 ml.

\section{Dos cámaras}

Desde la visión de 4 cámaras, sin movilizar el transductor, se rota el ángulo a $60^{\circ}-90^{\circ}$, donde se observa el VI, la Al y la orejuela izquierda. En esta visión se observa el ápex y es una buena ventana para detectar trombos tanto en la punta del ventrículo como en la orejuela.

\section{Tracto de salida del VI}

Finalmente, nuevamente sin movilizar el transduc-

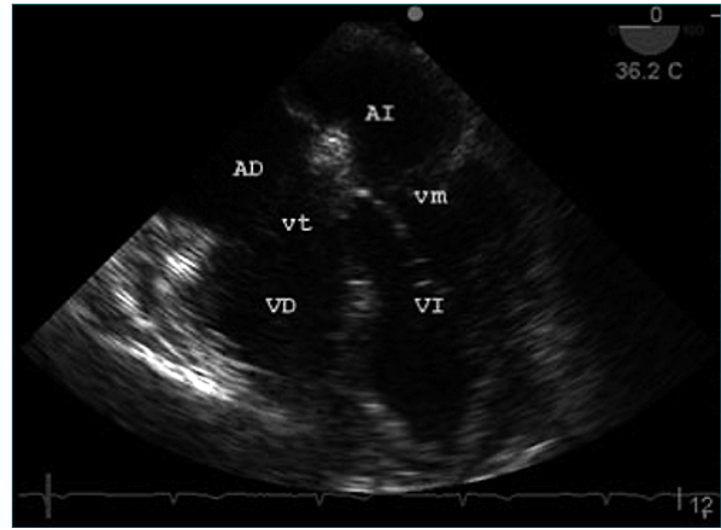

Figura 8. Imagen que se obtiene desde esófago medio, donde se observan las cuatro cámaras y sus válvulas. Se observa la aurícula derecha (AD), el ventrículo derecho (VD), la válvula tricúspide (vt), la aurícula izquierda (Al), el ventrículo izquierdo $(\mathrm{VI})$ y la válvula mitral (vm).

tor y cambiando la angulación a $120^{\circ}$ se obtiene una imagen del tracto de salida del VI.

\section{Transgástrico (aproximadamente a $40 \mathrm{~cm}$ de la arcada dentaria)}

\section{Eje corto intragástrico}

Se ingresa la sonda a estómago, donde es posible visualizar en un eje corto el ventrículo izquierdo a $0^{\circ}$ (Figura 9). En algunos pacientes es necesario anteflectar el transductor.

La visión transgástrica en eje corto a nivel de los

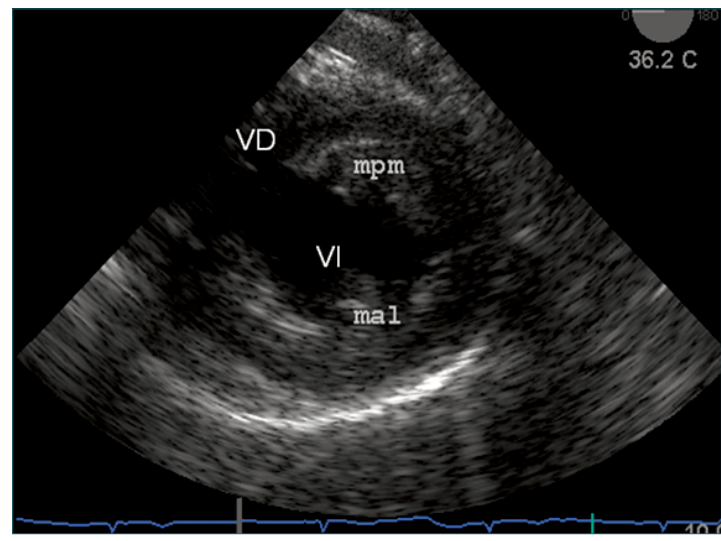

Figura 9. Imagen intragástrica del ventrículo izquierdo en su eje corto. Se observa el ventrículo izquierdo (VI), el ventrículo derecho (VD), el músculo papilar anterolateral (mal) y el músculo papilar posteromedial (mpm). 
músculos papilares es útil para detectar isquemia miocárdica, porque en esta zona es donde las tres arterias coronarias mayores tienen territorios que las representan: si bien pueden existir variaciones, en general la descendente anterior irriga la pared anterior, el septum anterior y parte de la pared anterolateral, la arteria circunfleja irriga la pared lateral y la coronaria derecha irriga la pared inferior, parte de la pared inferolateral y el septum posterior (Figura 10).

\section{Ecocardiografía transesofágica en cirugía no cardiaca}

Según las últimas guías norteamericanas publicadas, las razones para monitorizar con ETE de manera electiva durante cirugía no cardíaca, debieran incluir a todos aquellos pacientes cardiópatas en que se prevea que puedan existir complicaciones hemodinámicas, pulmonares o neurológicas perioperatorias[19]. Los pacientes cardiópatas pueden tener patología coronaria, falla ventricular, arritmias, valvulopatías e hipertensión pulmonar. El objetivo de la utilización de la ETE es la monitorización directa y en tiempo real del corazón y sus grandes vasos, para así realizar un diagnóstico precoz y guiar la terapia con drogas vasoactivas, betabloqueadores y fluidos en base a las imágenes y mediciones del miocardio y cavidades car-

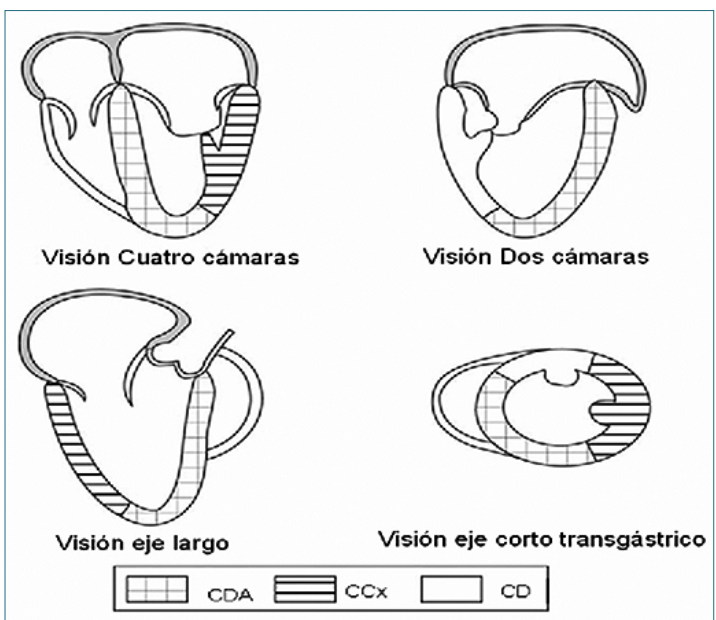

Figura 10. Esquema de los diferentes territorios irrigados por la arteria coronaria derecha (CD), circunfleja (CCX) y descendente anterior (CDA). En este esquema se muestra la visión transgástrica en eje corto, con representación de los territorios irrigados por las 3 arterias coronarias y, además, se esquematiza la irrigación de los territorios que se observan en las imágenes de eje largo. díacas obtenidas[20].

Existen diferentes parámetros ecocardiográficos que evalúan la función miocárdica intraoperatoria como son la fracción de eyección (FE) y el llenado VI. La FE es un buen índice de función sistólica que cuando está disminuida se correlaciona con un mayor riesgo de eventos luego de una cirugía no cardíaca. Las velocidades del llenado ventricular izquierdo evaluadas con doppler dan cuenta de la función diastólica. También se ha observado que la disfunción diastólica se asocia con un mayor número de eventos hemodinámicos posoperatorios, como hipotensión e hipertensión.

Existen dos escenarios posibles en relación con la monitorización con ETE:

- Ecocardiografía intraoperatoria "electiva" en casos con antecedentes cardiovasculares importantes y/o en que se espere un sangrado importante.

- Ecocardiografía intraoperatoria de "emergencia" en caso de un compromiso hemodinámico severo, en que no ha habido respuesta a terapia con volumen y vasopresores.

\section{Primer escenario: algunos ejemplos donde la ETE electiva puede ser útil.}

\section{Cirugía vascular}

Una de las indicaciones más frecuentes para monitorizar con ETE es durante el intraoperatorio de grandes cirugías vasculares, como por ejemplo, aneurismas de aorta. Está bien demostrado que los pacientes sometidos a cirugía vascular mayor tienen mayor riesgo de presentar isquemia miocárdica perioperatoria. La sensibilidad y especificidad de la ecocardiografía para la detección de nuevos eventos isquémicos es alta, por lo que su uso puede contribuir a identificar estos eventos en forma precoz, en relación con el uso exclusivo de electrocardioscopía. Sin embargo, la alta utilidad de la ETE en cirugía vascular mayor no sólo radica en detectar episodios de isquemia intraoperatoria, sino que también permite manejar los volúmenes cardiacos durante el clampeo aórtico y ajustarlos al momento del desclampeo (un signo claro de hipovolemia es el signo llamado "beso de los músculos papilares"). También es útil para evaluar el efecto de fármacos como betabloqueadores y, en el caso de indicar fármacos vasoactivos, es posible visualizar rápidamente sus efectos en la contractilidad miocárdica[21].

\section{Cirugía ortopédica}

Existe un grupo importante de pacientes añosos y portadores de múltiples patologías, entre ellas pa- 
tología cardiovascular relevante, que son sometidos a procedimientos no electivos, como fracturas de cadera, donde existe riesgo de sangrado y embolia pulmonar durante la cirugía. En estos pacientes, la visualización del material embolizado permitirá realizar el diagnóstico y, así, decidir la mejor terapia teniendo en cuenta que la respuesta hemodinámica dependerá de la magnitud de la carga embolizada y de su reserva funcional cardiopulmonar (Figura 11). Otro grupo de enfermos que presentan gran riesgo de sangrado, y en los que por consiguiente pudiera ser útil la monitorización con ETE es el de los pacientes sometidos a corrección de escoliosis, no obstante, la principal limitación para utilizar este tipo de monitoreo es la posición en prono, que impide un manejo adecuado de la sonda

\section{Cirugía abdominal, renal y urológica}

Muchos de estos pacientes son también añosos y portadores de patología cardiovascular crónica. La detección de isquemia intraoperatoria con ecocardiografía, al igual que en los casos descritos previamente, hará cambiar la conducta y plan anestésico tanto intraoperatorio como posoperatorio, derivando al paciente a unidades de cuidado de mayor complejidad, iniciando precozmente la administración de antiagregantes plaquetarios y eventualmente realizando estudio de la anatomía coronaria en hemodinamia. Existen cirugías en que, eventualmente, puede haber grandes cambios de volumen como prostatectomías radicales o tumorectomías renales. En el caso de cirugía de hipernefromas la ETE permite evaluar el grado de compromiso tumoral. Otra indicación muy interesante es durante la resección de una feocromocitoma, por tratarse de pacientes en que la volemia es muy difícil de estimar y donde existen claramente dos tiempos quirúrgicos antes y después de la resección del tumor.

\section{Neurocirugía}

Una de las primeras indicaciones de ETE durante cirugía no cardíaca fue la neurocirugía en posición sentada. Con el transductor instalado en esófago medio para monitorizar las cavidades cardíacas derechas es posible visualizar el ingreso de aire a estas cavidades. La magnitud de la embolización puede ser muy grande y en el caso de estos pacientes, la detección de embolia aérea por ecocardiografía resulta ser muy anterior al cambio de la curva de capnografía y al deterioro en el estado hemodinámico.

\section{Trauma}

En el trauma torácico agudo la ETE es una herra-

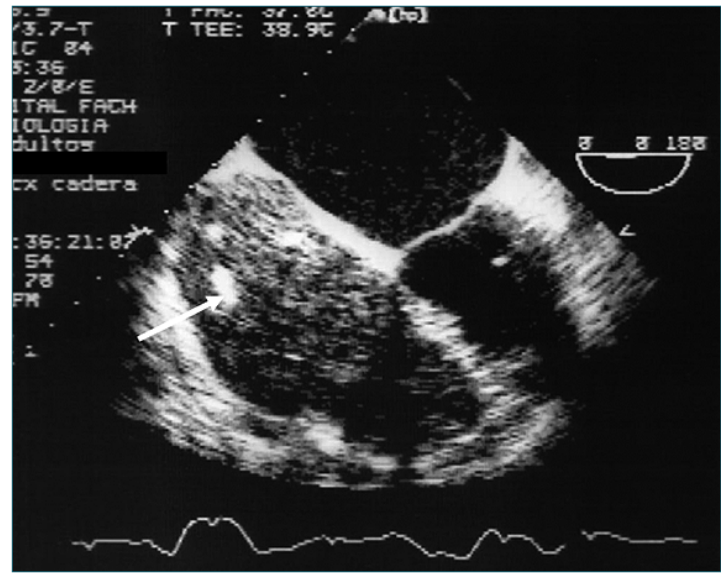

Figura 11. Imagen de 4 cámaras donde se observa una gran cantidad de material embolizado que ingresa a la AD y VD.

mienta de alta utilidad para evidenciar disección traumática de aorta, contusiones miocárdicas y lesión de grandes vasos. También se ha demostrado su eficiencia en el politraumatizado grave, no sólo para monitorizar su hemodinamia, sino que también para realizar nuevos diagnósticos, como taponamiento cardíaco y lesiones de miocardio. Se ha utilizado tanto la ETE como la ETT para monitorización de maniobras de resucitación cardiopulmonar y ha demostrado ser una herramienta efectiva.

\section{Segundo escenario: el "descalabro" hemodiná- mico}

En el caso de un severo compromiso hemodinámico durante una cirugía no cardíaca, que no responde a tratamiento, también está indicado el uso de ETE. En estos casos, independiente de las patologías de base del paciente, se ha demostrado la alta utilidad de la ecocardiografía para lograr un diagnóstico etiológico y así manejar la causa del deterioro de la hemodinamia. Además, su uso permite manejar y guiar la terapia que se indique al paciente, el uso de volumen, y el efecto en el miocardio de las diferentes drogas vasoactivas.

Es importante tener en cuenta que hipotensión no es sinónimo de hipovolemia. No siempre el manejo de una hipotensión es la administración de volumen. Existen pacientes que presentan isquemia masiva, taponamiento pericárdico y/o movimiento sistólico anterior (SAM) (acrónimo del inglés: Systolic Anterior Motion) del velo anterior de la válvula mitral.

Uno de los problemas de la ETE es el sobrediagnóstico o el subdiagnóstico por falta de experiencia y/o formación del operador. En Norteamérica y Eu- 
ropa la formación del anestesiólogo para realizar ecocardiografía ha sido dividida en niveles básico y avanzado. En el nivel básico el anestesiólogo debe ser capaz de reconocer todas las estructuras cardíacas, diagnosticar isquemia miocárdica, evaluar la hemodinamia y función ventricular; se recomienda para esto un mínimo de 150 exámenes. Es muy importante que sepa reconocer sus limitaciones, no aventure diagnósticos y solicite ayuda precozmente. En la etapa más avanzada deberá, además, manejar doppler para mediciones de gradientes y áreas, diagnosticar disección aórtica, endocarditis y trombos; para esto se requiere la realización de al menos 300 exámenes.

En conclusión: de este capítulo de ecocardiografía, se puede afirmar que la ETT ha permitido la difusión de la técnica a las especialidades que la requieren (urgencia cuidado intensivo, anestesia). La ETE permite la obtención de imágenes de excelente calidad, pero se necesita una sonda de alto costo y operadores muy bien entrenados.

\section{Referencias}

1. Feigebaum $\mathrm{H}$, Amstrong WF, Ryan T, editors. Feigebaum's echocardiography. 6th edn. Lippincott Williams and Wilkins, 2005, Capítulos 12,13 y 14.

2. de Groot-de Laat LE, ten Cate FJ, Vourvouri EC, van Domburg RT, Roelandt JR. Impact of hand-carried cardiac ultrasound on diagnosis and management during cardiac consultation rounds. Eur J Echocardiogr. 2005 Jun;6(3):196-201. https://doi. org/10.1016/j.euje.2004.09.013 PMID:15894238

3. Barbosa M, Nunes $C$. The potential of point of care ultrasound by non-experts to improve diagnosis and patients care. Heart. 2015;125-32. PMID:26552757

4. Via G, Hussain A, Wells M, Reardon R, ElBarbary M, Noble VE, et al.; International Liaison Committee on Focused Cardiac UltraSound (ILC-FoCUS); International Conference on Focused Cardiac UltraSound (ICFoCUS). International evidencebased recommendations for focused cardiac ultrasound. J Am Soc Echocardiogr. 2014 Jul;27(7):683.e1-33. https://doi. org/10.1016/j.echo.2014.05.001 PMID:24951446

5. Subramaniam B, Talmor D. Echocardiography for management of hypotension in the inten- sive care unit. Crit Care Med.

2007 Aug;35(8 Suppl):S401-7. https://doi.org/10.1097/01. CCM.0000270277.29661.3B PMID:17667465

6. Rose JS, Bair AE, Mandavia D, Kinser DJ. The UHP ultrasound protocol: a novel ultrasound approach to the empiric evaluation of the undifferentiated hypotensive patient. Am J Emerg Med. 2001 Jul;19(4):299-302. https://doi. org/10.1053/ajem.2001.24481 PMID:11447518

7. Faris JG, Veltman MG, Royse CF. Limited transthoracic echocardiography assessment in anaesthesia and critical care. Best Pract Res Clin Anaesthesiol. 2009 Sep;23(3):285-98. https://doi. org/10.1016/j.bpa.2009.02.008 PMID:19862888

8. Jensen MB, Sloth $E$, Larsen KM, Schmidt MB. Transthoracic echocardiography for cardiopulmonary monitoring in intensive care. Eur J Anaesthesiol. 2004 Sep;21(9):700-7. https:// doi.org/10.1097/00003643200409000-00006 PMID:15595582

9. Gunst M, Ghaemmaghami V, Sperry J, Robinson M, O'Keeffe $T$, Friese $R$, et al. Accuracy of cardiac function and volume status estimates using the bedside echocardiographic assessment in trauma/critical care.
J Trauma. 2008 Sep;65(3):509-

16. https://doi.org/10.1097/

TA.0b013e3181825bc5

PMID:18784562

10. Mandavia DP, Hoffner RJ, Mahaney K, Henderson SO. Bedside echocardiography by emergency physicians. Ann Emerg Med. 2001 Oct;38(4):377-82. https://doi. org/10.1067/mem.2001.118224 PMID:11574793

11. Denault A, Vegas A, Royse C. Bedside clinical and ultrasoundbased approaches to the management of hemodynamic instability-part I: focus on the clinical approach: continuing professional development. Can J Anaesth. 2014 Sep;61(9):843-64. https:// doi.org/10.1007/s12630-0140203-0 PMID:25169906

12. Nguyen VT, Ho JE, Ho CY, Givertz MM, Stevenson LW. Handheld echocardiography offers rapid assessment of clinical volume status. Am Heart J. 2008 Sep;156(3):537-42. https://doi. org/10.1016/j.ahj.2008.04.015 PMID:18760138

13. Algaba M, Oviedo A. Advantages of ultrasound in the emergency room. Crit Ultrasound. 2015;7(S1 Suppl 1):A17. https:// doi.org/10.1186/2036-7902-7S1-A17.

14. Beaulieu Y. Specific skill set and goals of focused echocardiography for critical care 
clinicians. Crit Care Med.

2007 May;35(5 Suppl):S144-9.

https://doi.org/10.1097/01.

CCM.0000260682.62472.67

PMID:17446773

15. Joseph MX, Disney PJ, Da Costa R, Hutchison SJ. Transthoracic echocardiography to identify or exclude cardiac cause of shock. Chest. 2004 Nov;126(5):1592-7. https:// doi.org/10.1378/chest.126.5.1592 PMID:15539732

16. Manno E, Navarra M, Faccio L, Motevallian M, Bertolaccini L, Mfochivè A, et al. Deep impact of ultrasound in the intensive care unit: the "ICUsound" protocol. Anesthesiology. 2012 Oct;117(4):801-9. https://doi.org/10.1097/ ALN.0b013e318264c621 PMID:22990179
17. Beaulieu Y, Marik PE. Bedside ultrasonography in the ICU: part 1. Chest. 2005 Aug;128(2):881-95. https://doi. org/10.1378/chest.128.2.881 PMID:16100182

18. Beaulieu Y, Marik PE. Bedside ultrasonography in the ICU: part 2. Chest. 2005 Sep;128(3):1766-81. https://doi. org/10.1378/chest.128.3.1766 PMID:16162786

19. Cahalan MK, Stewart W, Pearlman A, Goldman M, SearsRogan P, Abel M, et al.; Society of Cardiovascular Anesthesiologists; American Society of Echocardiography Task Force. American Society of Echocardiography and Society of Cardiovascular Anesthesiologists task force guidelines for training in perioperative echocardiography. J Am Soc Echocardiogr. 2002 Jun;15(6):647-52. https://doi. org/10.1067/mje.2002.123956 PMID:12050607

20. Catena E, Mele D. Role of intraoperative transesophageal echocardiography in patients undergoing noncardiac surgery. J Cardiovasc Med (Hagerstown). 2008 Oct;9(10):9931003. https://doi.org/10.2459/ JCM.0b013e32830bf655 PMID:18799961

21. Schulmeyer C, Farías J, Rajdl E, de La Maza J, Labbé M. Utility of transesophageal echocardiography during severe hypotension in non-cardiac surgery. Rev Bras Anestesiol. 2010 Sep-Oct;60(5):513-21. PMID:20863931 